Contents List available at RAZI Publishing

\title{
FLOOD MITIGATION MEASURES USING INTUITIONISTIC FUZZY DEMATEL METHOD
}

Norzanah Abd Rahman*, Zamali Tarmudi, Munirah Rossdy, Fatihah Anas Muhiddin

Department of Mathematics, Faculty of Computer and mathematical Sciences, Universiti Teknologi MARA (UiTM), Locked Bag 71, 88997 Kota Kinabalu, Sabah, Malaysia.

*Corresponding Author e-mail: norzanah.abdrahman@gmail.com

This is an open access article distributed under the Creative Commons Attribution License, which permits unrestricted use, distribution, and reproduction in any medium, provided the original work is properly cited.

\section{ARTICLE DETAILS}

\section{ARTICLE HISTORY:}

Received 12 May2017

Accepted 12 July 2017

Available online 10 September 2017

\section{KEYWORDS}

Flood mitigation measures, Intuitionistic Fuzzy DEMATEL method, Sensitivity Analysis

\section{ABSTRACT}

Flood is a natural disaster induced by climate change that resulted in the losses of lives, damages to property, and disrupts the daily activities of local community. Thus, the flood mitigation measures are developed to reduce the impact of flood in our country. The aim of this paper is; to propose IF-DEMATEL method and deal with the uncertainty of input data set of flood mitigation measures, and to validate it using sensitivity analysis. Here, this method is used for flood mitigation measures comprise drainage improvements, barriers, wet flood proofing, dry flood proofing, elevation, relocation, and acquisition. A numerical example from the flood control project selection proposed by a researcher which was adopted to show the applicability of the proposed method. The result shows that the flood mitigation measures are placed based on their priority. Although the rank of flood mitigation measures is sensitive to changes based on the weight of criteria but the best measures is remaining unchanged.

\section{INTRODUCTION}

Flooding is known as the most reported natural disaster worldwide induced by natural phenomenon and human activities [1-3]. Flood causes significant losses in terms of lives [4], effects on human health [5], kills the plants [6] damages to property (tangible and intangible) [7], and disrupts the daily activities of local community [4].

As a response to these loses, the government concentrated on managing the floodwaters based on the flood management strategies framework to lessen the flood problems [8]. The strategies are the establishing appropriate and workable institutions for implementing flood control works and flood relief operations, carrying out river basin studies, and implement flood mitigation measures (structural, non-structural measure, and contingency) $[9,10]$. The flood mitigation measure is a long-term effort to lessen the impact of disaster by managing the effects, rather than trying to avert it totally [8]. Almost, every country has their own strategies to manage the flood, as in the United States, they executed the flood damage reduction projects under consideration of large-scale and small-scale capital projects, ecosystem-based projects, landuse management, and flood warning and preparedness [11].

However, the adaption of flood mitigation measures can be complex and difficult since it involves uncertainty of the future changes and limiting factors. Thus, bottomless consideration on possible significance factors and limitation are needed. For instance, Devesh Sharma, [12] emphasized that the measure is considered based on lesson learned from previous flood events, future scenarios (climatic, socio-economic development) and local condition (topography, weather, population, area, land-use, institutional set-ups, and so on). In previous pilot studies, the researchers applied the qualitative approach such as participatory approach that require a contribution of the people or community in decision making process [13-16]. Likewise, 26 River Basin Studies in Malaysia has been carried out for river flood areas to draw up the suitable flood maps and practical projects [17].

However, this qualitative approach cannot cope with the uncertainty in future changes such as impossibility to predict future human behavior in terms of population change, social and economic development, effectiveness of the climate mitigation policy, and adaptation to climate change impacts [18]. Therefore, a mathematical method such as Fuzzy Multi-Criteria Decision Making (FMCDM) are needed to model an algorithm that can solve uncertainty, multiple and conflicting criteria aspect in the decision-making process [19]. In previous studies, it has been combined with the hydrological model, Geographical Information Systems (GIS), and Artificial Intelligence (AI) to solve spatial problems in flood environment. For example, Nirupama and Slobodan, [20] used a Spatial Fuzzy Compromise Programming (SFCP) in the GIS environment to select the best strategies in floodplain management strategies. Costa et al., [21] proposed (Measuring Attractiveness by Categorical Based Evaluation Technique) MACBETH to evaluate flood control options for the water catchment. Moreover, a type-2 fuzzy Technique for Order Preference by Similarity to an Ideal Solution (TOPSIS) method is applied to select the best alternatives among several flood controls which are reservoir, dikes, and channel improvement as well as diversion scheme [22]. Recently, Banihabib and Laghabdoost, [23] investigated flood management alternatives based on sustainable development criteria (SDC) using an Elimination ET Choice Translating Reality (ELECTRE-III).

In this paper, we want to prioritize the flood mitigation measures using Intuitionistic Fuzzy Decision-Making Trial and Evaluation Laboratory (IFDEMATEL) method. This method will be used to deal with the uncertainty of input data set of flood mitigation measures. We believe that IF-DEMATEL method is suitable approach to assist the decision makers (DMs) to make choice in flood mitigation measure that involves uncertainty, multiple and complex in nature. In addition, this method has proven to possess an excellent result by establishing a contextual relationship among criteria [24-26]. In this paper, we used a sensitivity analysis (SA) to validate our methodology. A numerical example is presented in this paper by adopting [22] to show the applicability and practicality of our proposed method.

Thus, the remainder of this paper is presented as follows: After a brief introduction in section I, section II will present the theoretical concepts that comprise preliminaries of the IFS, DEMATEL, and proposed methodology (IF-DEMATEL). Section III portrays the application of the IF-DEMATEL together with the result of a numerical example, before the conclusion made in section IV.

\section{THE THEORITICAL CONCEPT AND PROPOSED METHODOLOGY}


In this section, basic definitions of both method are briefly explained for the references proposes.

Intuitionistic fuzzy set (IFs) is a generalization of fuzzy set that has an ability to degree the uncertainty in decision maker choice of alternatives (Atanassov, 1986).

\section{Definition 1:}

Let a set $\mathrm{X}$ be fixed. An IFs in in $\mathrm{X}$ is defined as an object of the following form

$A=\left\{\left\langle x, \mu_{A}(x), v_{A}(x)\right\rangle \mid x \in X\right\}$.

Where the functions: $\mu_{A}: X \rightarrow[0,1]$ and $v_{A}: X \rightarrow[0,1]$ define the degree of membership and the degree of non-membership of the element $x \in X, \quad$ respectively, and for every $x \in X$ : $0 \leq \mu_{A}(x)+v_{A}(x) \leq 1$

\section{Definition 2:}

The value of $\pi_{A}(x)=1-\pi_{A}(x)-v_{A}(x)$ is called the degree of non-determinacy (or uncertainty) of the element $x \in X$ to the IFs A.

\section{Theorem 1:}

Suppose $\tilde{P}=\left\langle\left(p_{1}, p_{2}, p_{3}, p_{4} ; p_{1}^{\prime}, p_{2}^{\prime}, p_{3}^{\prime}, p_{4}^{\prime}\right)\right\rangle$ be a Trapezoidal Intuitionistic Fuzzy Number (TrIFN) in $X$. When $\stackrel{x-p_{1}}{ }, \frac{p_{4}-x}{p_{2}-p_{1}}, \frac{p_{2}^{\prime}-x}{p_{4}-p_{3}}, \frac{x-p_{3}^{\prime}}{p_{2}-p_{1}^{\prime}}$

$p_{2}-p_{1} \quad p_{4}-p_{3} \quad p_{2}^{\prime}-p_{1}^{\prime} \quad p_{4}^{\prime}-p_{3}^{\prime}$

$p^{\prime}{ }_{1} \leq p_{1} \leq p^{\prime}{ }_{2} \leq p_{2} \leq p_{3} \leq p^{\prime}{ }_{3} \leq p_{4} \leq p^{\prime}{ }_{4} \in X$, the expected value is calculated as follows

$\tilde{E V(P)}=\frac{1}{8}\left(p_{1}+p_{2}+p_{3}+p_{4}+p_{1}^{\prime}+p_{2}^{\prime}+p_{3}^{\prime}+p_{4}^{\prime}\right)$

\subsection{DEMATEL Method}

DEMATEL method is one of the popular technique that can visualize the relationship of effect and cause group in digraph by establishing the worthy and important of factors and sub-factors [27]. The basic steps are:

Forming the direct-relation (average) matrix using equation below

$A^{p}=\left[a_{i j}^{p}\right]_{n x n}$

Where,

$\left[a_{i j}\right]_{n x n}=\frac{1}{p} \sum_{h=1}^{p}\left[a_{i j}\right]_{n x n}$

Normalizing the initial direct relation matrix using equation (4)

$D=\frac{A^{p}}{\max \left\{\max \sum_{j=1}^{n} a_{i j}, \max \sum_{i=1}^{n} a_{i j}\right\}}$

Assuming that the power of matrix $\mathrm{D}^{\mathrm{m}}$ ( $\mathrm{m}$-direct influence) would converge to zero matrix. The total relation matrix, $\mathrm{T}$ can be obtained by following formula:

$$
\begin{aligned}
& \lim _{m \rightarrow \infty} D^{m}=[0]_{n x n} \\
& T= \sum_{m}^{\infty} D_{i}=D+D^{2}+D^{3} \ldots D^{m} \\
&=D\left(1++D+D^{2}+D^{3} \ldots D^{m-1}\right) \\
&=D(I-D)^{-1}\left(I-D^{m}\right) \\
&=D(I-D)^{-1}
\end{aligned}
$$

Where,

$I$ is an identity matrix.

\section{THE PROPOSED METHODOLOGY}

In this research, we modified the IF-DEMATEL proposed by Razieh Keshavarzfard and Ahmad Makui, [26] as shown in the figure 1.

In step 1,2 , and $3, p$ respondents are chosen to make the sets of pairwise comparisons between the criteria based on triangular IF linguistic phrases. Here, we used trapezoidal IF linguistic phrases which are Very High Influence (VH), High Influence (H), Medium influence (M), Low influence (L) and No Influence (No) as shown in Table 1.

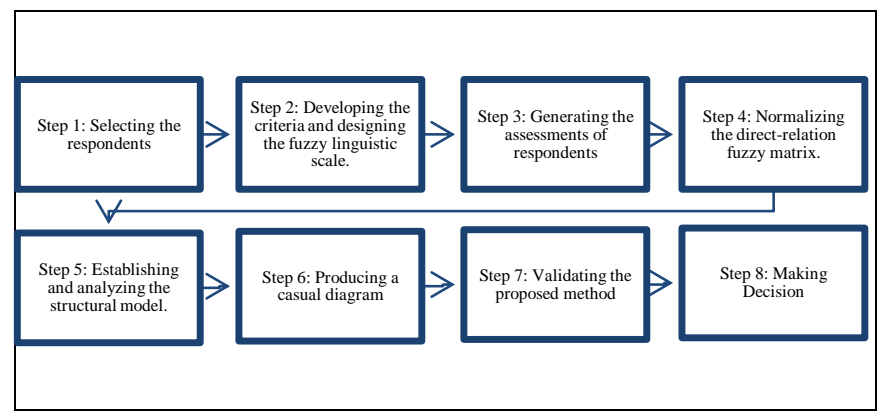

Figure 1: IF-DEMATEL method

Table 1: The Trapezoidal Intuitionistic Fuzzy Linguistic Scale

\begin{tabular}{|c|c|c|}
\hline $\begin{array}{c}\text { Linguistic } \\
\text { phrases }\end{array}$ & TrIFN & $\begin{array}{c}\text { Expected } \\
\text { values }\end{array}$ \\
\hline VH & $\langle(1,1,1,1),(1,1,1,1)\rangle$ & 1.00 \\
\hline $\mathbf{H}$ & $\langle(0.7,0.8,09,1),(0.7,0.8,09,1)\rangle$ & 0.85 \\
\hline $\mathbf{M}$ & $\langle(0.3,0.4,05,0.6),(0.2,0.4,05,0.7)\rangle$ & 0.45 \\
\hline $\mathbf{L}$ & $\langle(0,0.1,0.20 .3),(0,0.1,0.20 .3)\rangle$ & 0.15 \\
\hline $\mathbf{N}$ & $\langle(0,0,0,0),(0,0,0,0)\rangle$ & 0.00 \\
\hline
\end{tabular}

The sets of pairwise comparisons of each respondent $\tilde{A}^{(h)}$ is the directrelation IF matrix of expert $h$.

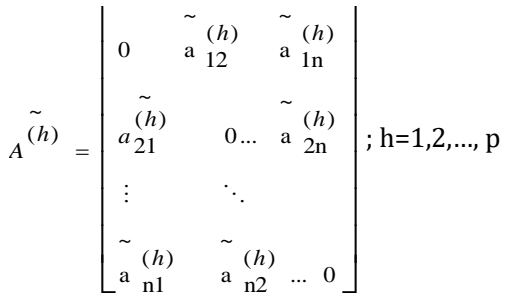

$$
\tilde{a}_{i j}^{(h)}=\left(x_{i j}, y_{i j}, z_{i j} ; x_{i j}^{\prime}, y_{i j}^{\prime}, z_{i j}^{\prime}\right)
$$

In step 4, the matrix $\tilde{A}^{(h)}$ is normalized using equation (8)

$$
\sim_{B}^{(h)} \quad \sim_{s}^{(h)}=\left(\frac{a_{i j}}{s}\right)\left(\frac{x_{i j}}{s}, \frac{y_{i j}}{s}, \frac{z_{i j}}{s} ; \frac{x_{i j}}{s}, \frac{y_{i j}}{s}, \frac{z_{i j}}{s}\right)
$$

Where, $s=\max \left(\sum_{j=1}^{n} z_{i j}^{\prime}\right) \quad 1 \leq i \leq n$

In step 5 , we modified

this step to calculate the average matrix of $B$ from eq. (9) to equation (10).

$$
\left.\tilde{\sim}^{(1)} \tilde{B}^{(2)} \oplus \tilde{B}^{(p)} \oplus \ldots \oplus \tilde{B}^{(p)}\right) / p
$$

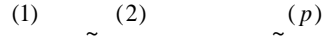

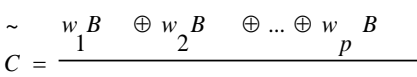

$$
\begin{aligned}
& \sum_{h=1}^{p} w_{h}
\end{aligned}
$$


Where, $w_{h}$ is the importance of $\mathrm{h}^{\text {th }}$ respondents based on the importance weights of respondents that presented in the Table 2.

Table 2: The Importance Weight of Respondents

\begin{tabular}{|c|c|c|c|}
\hline $\begin{array}{c}\text { Linguisti } \\
\text { c } \\
\text { Variable }\end{array}$ & $\begin{array}{c}\text { Fuzzy } \\
\text { Numbers }\end{array}$ & $\begin{array}{c}\text { Mean of Fuzzy } \\
\text { Numbers }\end{array}$ & Respondent \\
\hline $\begin{array}{c}\text { Very } \\
\text { High, VH }\end{array}$ & $(0.7,0.9,1)$ & 0.8667 & \\
\hline High, H & $(0.5,0.7,0.9)$ & 0.7 & 1 \\
\hline $\begin{array}{c}\text { Medium, } \\
\text { M }\end{array}$ & $(0.3,0.5,0.7)$ & 0.5 & 3 \\
\hline Low, L & $(0.1,0.3,0.5)$ & 0.3 & \\
\hline $\begin{array}{c}\text { Very } \\
\text { Low, VL }\end{array}$ & $(0,0.1,0.3)$ & 0.13333 & \\
\hline
\end{tabular}

Then, IF number is converted into crisp value using Theorem 1 (eq. 2) before the total direct relation $D$ is computed using equation (11) as follows:

$$
\tilde{\mathrm{D}}=\tilde{C}(I-C) \tilde{C}^{-1}
$$

In step 6, we produce a casual diagram by calculating the sum of rows and sum of columns are separately denoted as vector $\tilde{D_{i}}$ and vector $\tilde{R_{i}}$. The horizontal axis vector or prominence, $\left(D_{i}+R_{i}\right)$ represents how much importance the criterion has. The vertical axis or relation, $\left(\tilde{D_{i}}-\tilde{R}_{i}\right)$ divides the criteria into cause group (negative values) and effect group (positive values). The causal diagram can be acquired by mapping the dataset of the $\left(\left(D_{i}+R_{i}\right),\left(D_{i}-R_{i}\right)\right)$.

The importance of criteria is calculated by the following equation:

$\omega_{i}=\left\{\left(D_{i}+R_{i}\right)^{2},\left(\left(D_{i}-R_{i}\right)^{2}\right\}^{1 / 2}\right.$

The importance of any criterion can be normalized as follows:

$$
W_{i}=\frac{\omega_{i}}{\sum_{i=1}^{n} \omega_{i}}
$$

In step 7, the SA is performed using different weight of respondent 1.

Finally, in step 8, the flood mitigation measures can be prioritized based on the importance of criteria that are computed in step 6.

\section{APPLICATION}

For illustration example, the criteria of case study from [22] was adopted for flood mitigation measures (see Table 3 ).

Step 1: Three respondents from Department of Irrigation and Drainage (DID) is selected based on their knowledge and skill on the case study.

Step 2: The respondents are required to evaluate four criteria (C) of seven flood mitigation measures (A) based on her/his opinion (see Table 3 and 4).

Table 3: The Criteria of Flood Mitigation Measures

\begin{tabular}{|c|l|}
\hline $\mathbf{C}$ & \multicolumn{1}{|c|}{ Remarks } \\
\hline $\mathbf{C}_{\mathbf{1}}$ & $\begin{array}{l}\text { Project cost: Operations and maintenance cost, project } \\
\text { benefits, reliability economic parameter }\end{array}$ \\
\hline $\mathbf{C}_{\mathbf{2}}$ & $\begin{array}{l}\text { Social acceptability: Effect on demographic, effect on } \\
\text { infrastructure, recreation activity }\end{array}$ \\
\hline $\mathbf{C}_{\mathbf{3}}$ & $\begin{array}{l}\text { Environmental aspect: Water quality, nature } \\
\text { conservation, soil impact, landscape. }\end{array}$ \\
\hline $\mathbf{C}_{4}$ & $\begin{array}{l}\text { Technical: Lifetime, adaptability, level of protection, } \\
\text { technical complexity, flexibility }\end{array}$ \\
\hline
\end{tabular}

Sources: Nurnadiah Zamri [22]

Table 4: The Flood Mitigation Measures

\begin{tabular}{c|c}
\hline $\mathbf{A}$ & Function \\
\hline $\mathbf{A}_{\mathbf{1}}$ & Drainage improvement \\
\hline $\mathbf{A}_{\mathbf{2}}$ & Barriers \\
\hline $\mathbf{A}_{\mathbf{3}}$ & Wet Flood Proofing \\
\hline
\end{tabular}

\begin{tabular}{l|c}
\hline $\mathbf{A}_{\mathbf{4}}$ & Dry Flood Proofing \\
\hline $\mathbf{A}_{\mathbf{5}}$ & Elevation \\
\hline $\mathbf{A}_{\mathbf{6}}$ & Relocation \\
\hline $\mathbf{A}_{\mathbf{7}}$ & Acquisition \\
\hline
\end{tabular}

Step 3: The assessment data of respondent 1 is gathered as in Table 5.

Table 5: The Assessment Data of Respondent 1 for $A_{1}$

\begin{tabular}{|l|c|c|c|c|}
\hline & $\mathrm{C}_{1}$ & $\mathrm{C}_{2}$ & $\mathrm{C}_{3}$ & $\mathrm{C}_{4}$ \\
\hline $\mathrm{C}_{1}$ & 0 & $\mathrm{VH}$ & $\mathrm{L}$ & $\mathrm{L}$ \\
\hline $\mathrm{C}_{2}$ & $\mathrm{H}$ & 0 & $\mathrm{M}$ & $\mathrm{H}$ \\
\hline $\mathrm{C}_{3}$ & $\mathrm{~L}$ & $\mathrm{H}$ & 0 & $\mathrm{~L}$ \\
\hline $\mathrm{C}_{4}$ & $\mathrm{M}$ & $\mathrm{H}$ & $\mathrm{L}$ & 0 \\
\hline
\end{tabular}

Step 4: The direct-relation matrix is defined from the assessment data of respondent. The normalized initial direct-relation matrix is calculated using eq. (8).

Step 5: The average of normalize direct-relation matrix is computed using eq. (10). The total relation matrix is obtained using eq. (11) as shown in table 6.

Table 6: The Total Relation Matrix for

$\mathrm{A}_{1}$

\begin{tabular}{|l|c|c|c|c|}
\hline & $\mathbf{C}_{1}$ & $\mathbf{C}_{\mathbf{2}}$ & $\mathbf{C}_{\mathbf{3}}$ & $\mathbf{C}_{\mathbf{4}}$ \\
\hline $\mathbf{C}_{\mathbf{1}}$ & 1.11382 & -0.37218 & 0.011118 & -0.06232 \\
\hline $\mathbf{C}_{\mathbf{2}}$ & -0.288598 & 1.26171 & -0.26702 & -0.28579 \\
\hline $\mathbf{C}_{\mathbf{3}}$ & 0.0059143 & -0.28259 & 1.06899 & -0.02956 \\
\hline $\mathbf{C}_{4}$ & -0.091084 & -0.3165 & 0.025255 & 1.10031 \\
\hline
\end{tabular}

Step 6: The causal diagram is obtained as in Figure 2.

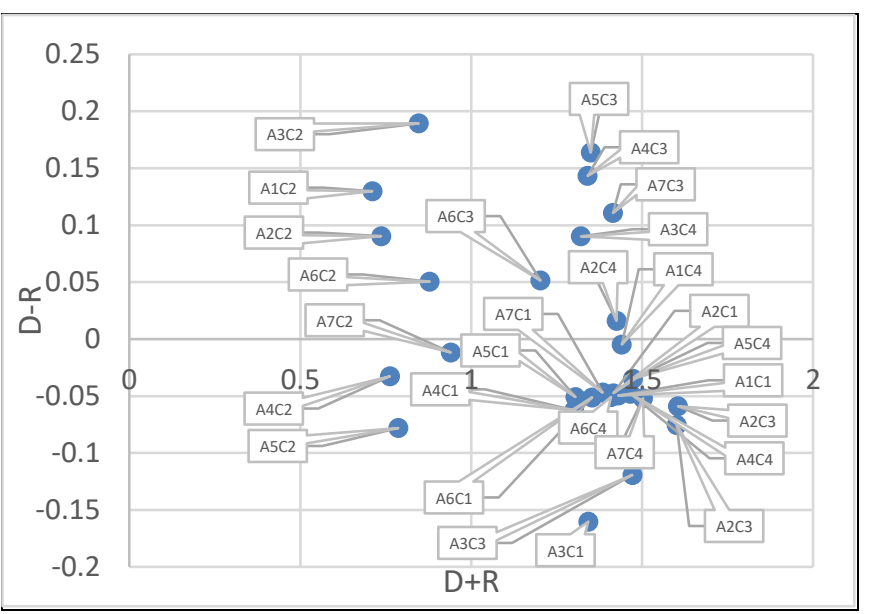

Figure 2: Total Causal relationship

Step 7: The sensitivity analysis will be performed for the IF-DEMATEL method using different weight of respondent 1 which is 0.5 (Medium) as shown in Table 7.

Table 7: The Importance Criteria

\begin{tabular}{|c|c|c|}
\hline $\mathbf{C}$ & $\begin{array}{c}\text { Importance } \\
\text { of Criteria } \\
\text { (actual) }\end{array}$ & $\begin{array}{c}\text { Importance } \\
\text { of Criteria } \\
\text { (SA) }\end{array}$ \\
\hline $\mathbf{A}_{\mathbf{1}} \mathbf{C}_{\mathbf{1}}$ & 8 & 2 \\
\hline $\mathbf{A}_{\mathbf{1}} \mathbf{C}_{\mathbf{2}}$ & 28 & 21 \\
\hline $\mathbf{A}_{\mathbf{1}} \mathbf{C}_{\mathbf{3}}$ & 2 & 4 \\
\hline $\mathbf{A}_{\mathbf{1}} \mathbf{C}_{\mathbf{4}}$ & 7 & 18 \\
\hline $\mathbf{A}_{\mathbf{2}} \mathbf{C}_{\mathbf{1}}$ & 11 & 11 \\
\hline $\mathbf{A}_{\mathbf{2}} \mathbf{C}_{\mathbf{2}}$ & 27 & 28 \\
\hline $\mathbf{A}_{\mathbf{2}} \mathbf{C}_{\mathbf{3}}$ & 1 & 1 \\
\hline $\mathbf{A}_{\mathbf{2}} \mathbf{C}_{\mathbf{4}}$ & 9 & 9 \\
\hline $\mathbf{A}_{\mathbf{3}} \mathbf{C}_{\mathbf{1}}$ & 16 & 12 \\
\hline $\mathbf{A}_{\mathbf{3}} \mathbf{C}_{\mathbf{2}}$ & 24 & 25 \\
\hline $\mathbf{A}_{\mathbf{3}} \mathbf{C}_{\mathbf{3}}$ & 4 & 3 \\
\hline $\mathbf{A}_{\mathbf{3}} \mathbf{C}_{\mathbf{4}}$ & 18 & 13 \\
\hline $\mathbf{A}_{\mathbf{4}} \mathbf{C}_{\mathbf{1}}$ & 20 & 19 \\
\hline $\mathbf{A}_{\mathbf{4}} \mathbf{C}_{\mathbf{2}}$ & 26 & 26 \\
\hline
\end{tabular}




\begin{tabular}{|l|c|c|}
\hline $\mathbf{A}_{\mathbf{4}} \mathbf{C}_{\mathbf{3}}$ & 17 & 16 \\
\hline $\mathbf{A}_{\mathbf{4}} \mathbf{C}_{\mathbf{4}}$ & 6 & 6 \\
\hline $\mathbf{A}_{\mathbf{5}} \mathbf{C}_{\mathbf{1}}$ & 19 & 20 \\
\hline $\mathbf{A}_{\mathbf{5}} \mathbf{C}_{\mathbf{2}}$ & 25 & 27 \\
\hline $\mathbf{A}_{\mathbf{5}} \mathbf{C}_{\mathbf{3}}$ & 19 & 17 \\
\hline $\mathbf{A}_{\mathbf{5}} \mathbf{C}_{\mathbf{4}}$ & 5 & 7 \\
\hline $\mathbf{A}_{\mathbf{6}} \mathbf{C}_{\mathbf{1}}$ & 15 & 15 \\
\hline $\mathbf{A}_{\mathbf{6}} \mathbf{C}_{\mathbf{2}}$ & 23 & 24 \\
\hline $\mathbf{A}_{\mathbf{6}} \mathbf{C}_{\mathbf{3}}$ & 21 & 22 \\
\hline $\mathbf{A}_{\mathbf{6}} \mathbf{C}_{\mathbf{4}}$ & 12 & 14 \\
\hline $\mathbf{A}_{\mathbf{7}} \mathbf{C}_{\mathbf{1}}$ & 13 & 10 \\
\hline $\mathbf{A}_{\mathbf{7}} \mathbf{C}_{\mathbf{2}}$ & 22 & 23 \\
\hline $\mathbf{A}_{\mathbf{7}} \mathbf{C}_{\mathbf{3}}$ & 10 & 8 \\
\hline $\mathbf{A}_{\mathbf{7}} \mathbf{C}_{\mathbf{4}}$ & 3 & 5 \\
\hline
\end{tabular}

area, cross river state, Nigeria. International Journal of Humanities and Social Science, 1 (9), 98-104.

[7] Alan, W., Donald, H., Tom, B., Amy, T., and Andrew, B. 2007. Exploring the social impacts of flood risk and flooding in Scotland. Blackwell's Bookshop, South Bridge, Edinburgh.

[8] Department of Irrigation and Drainage [DID]. 2009. Volume 1: Flood management. Retrieved from www. http://forum.mygeoportal.gov.my/smanre/aduan/Volume1_Flood\%20 Management.pdf.

[9] Hiew, K. L. 1996. Flood mitigation and flood risk management in Malaysia. Proceeding of International Workshop on Floodplain Risk Management, 11, pp. 205-216.

[10] Natural Resources Office Sabah. 1994. Water resources master plan: Final report-overview, 1-75

Step 8: Finally, the flood mitigation measures is prioritize based on the mean of the importance criteria obtained using eq. (12-13) as presented in Table 8.

Table 8: The rank of measures

\begin{tabular}{|c|c|c|}
\hline Measure & Mean of importance of criteria & Rank \\
\hline $\mathbf{A}_{\mathbf{1}}$ & 0.1472 & 2 \\
\hline $\mathbf{A}_{\mathbf{2}}$ & 0.1470 & 3 \\
\hline $\mathbf{A}_{\mathbf{3}}$ & 0.1422 & 4 \\
\hline $\mathbf{A}_{\mathbf{4}}$ & 0.1382 & 6 \\
\hline $\mathbf{A}_{\mathbf{5}}$ & 0.1396 & 5 \\
\hline $\mathbf{A}_{\mathbf{6}}$ & 0.1373 & 7 \\
\hline $\mathbf{A}_{\mathbf{7}}$ & 0.1486 & 1 \\
\hline
\end{tabular}

\section{CONCLUSION}

Finding revealed that, the environmental aspect of barriers $\left(\mathrm{A}_{2} \mathrm{C}_{3}\right)$ has the highest score in $\left(D_{i}+R_{i}\right)$ as shown in Figure 2. This indicate that it has the relative significance of the flood mitigation measures. The project cost of wet flood proofing $\left(\mathrm{A}_{3} \mathrm{C}_{1}\right)$ are the most influenced by other criteria as it $\left(D_{i}-R_{i}\right)$ score negative among other criteria in the effect group. The importance of criteria is sensitive to change of the importance weight of respondent however the highest importance of criteria is remaining unchanged (see Table 7). Overall, we must consider both prominence and relation ranking and according to Figure 2, environmental aspect of acquisition $\left(\mathrm{A}_{7} \mathrm{C}_{3}\right)$ is more significance than $\left(\mathrm{A}_{2} \mathrm{C}_{3}\right)$. In this paper, we have determined that acquisition is the priority of flood mitigation measures which has the highest importance criteria which is 0.1486 followed by drainage improvement, barriers, wet flood proofing, elevation, dry flood proofing, and relocation (see Table 8).

\section{ACKNOWLEDGEMENT}

This research was supported by Grant from Malaysian of Higher Education (MOHE) for "Bifuzzy Set Refinement" code: 600-RMI/RAGS 5/3 (148/2014).

\section{REFERENCES}

[1] Department of Irrigation and Drainage [DID]. 2007. Flood and drought management in Malaysia. pp. 1-39. Retrieved from http://www.met.gov.my.

[2] Water and Energy Consumer Association of Malaysia [WECAM]. 2013. Malaysia: Flood mitigation and adaptation. pp. 1-14. Retrieved from http://www.wecam.org.my.

[3] Lawal, D.U., Matori, A. N., Hashim, A.M., Yusof, K.W., and Chandio, I.A. 2012. Natural flood influencing factors: A case study of Perlis, Malaysia. International Conference on Civil, Offshore and Environmental Engineering (12-14 June 2012). Kuala Lumpur.

[4] Umar, C., M. 2007. Disaster mitigation support and management in Malaysia, 1-38. Prime Minister's Department Malaysia, Malaysia.

[5] Torti, J. 2012. Floods in Southeast Asia: A health priority. School of Public Health, University of Alberta, Edmonton, Alberta, Canada, 2 (2), doi: $10.7189 /$ jogh.02.020304.

[6] Eni, Devalsam, I., Atu, Joy, E., Oko, Comfort, O., Ekwok, and Innocent. 2011. Flood and its impact on farmlands in Itigidi, Abi local government

[11] Lauren, D. 2013. Proactive flood and drought management: A selection of applied strategies and lessons learned from around the United States, 1-63. American Water Resources Association, Virginia.

[12] Devesh Sharma. 2012. Situation analysis of flood disaster in South and Southeast Asia - a need of integrated approach. International Journal of Science, Environment and Technology, 1 (3), 167-173.

[13] Ramsbottom. 2005a. Sustainable flood mitigation strategies pilot study 1: community flood mitigation activities. Report EX 5129. HR Wallingford.

[14] Ramsbottom. 2005b. Sustainable flood mitigation strategies pilot study 2: community flood mitigation activities. Report EX 5130. HR Wallingford.

[15] Mathias, S., Morgan De Dapper, Chris, M. M. \& Antonio, Y. 2011. Participatory approach for integrated basin planning with focus on disaster risk reduction: The case of the Limpopo River. Water, 3, 737-763. doi: $10.3390 /$ w3030737.

[16] Vojinovic, Golub, D., Weesakul, S., Keerakamolchai, W., Hirunsalee S., Meesuk, V., Abbott, M. 2014. Merging quantitative and qualitative analyses for flood risk assessment at heritage sites, the case of Ayutthaya Thailand. 11th International Conference on Hydroinformatics [HIC 2014], New York City, USA.

[17] Chia, C. W. 2004. Managing Flood Problems in Malaysia. Buletin Ingenieur 22, June-August 2004: Board of Engineers Malaysia, 38-43. Kuala Lumpur.

[18] Ali Chavoshian and Kuniyoshi Takeuchi (Eds.). 2011. Large-scale floods report book: lessons learned and best practices for flood disaster managers and policy makers. ICHARM Book Series, 1, 1-205.

[19]Jie, L., Guangquan, Z. D. R., and Fengjie, W. 2006. Multi-objective group decision making: methods, software and applications with fuzzy set technique. London: Imperial College Press.

[20] Nirupama, and Slobodan, P. S. 2002. A spatial fuzzy compromise approach for flood disaster management (Doctoral thesis, The Institute of Catastrophic Loss Reduction, London, Ontario). Retrieved from http://ir.lib.uwo.ca/cgi/viewcontent.cgi?article=1004\&context=wrrr.

[21] Costa, C. A. B. E., Silva, P. A. D., Coria, F. N. 2003. Multicriteria evaluation of flood control measures: The case of Ribeira Do Livramento The London School of Economics and Political Science, London.

[22] Zamri, N., Abdullah, L., Hitam, M.S., Noor, N.M.M., Jusoh, A. 2013. A type-2 multi criteria decision making approach for flood control project selection. Australian Journal of Basic and Applied Sciences, 7 (10), 180191.

[23] Banihabib, M. E., and Laghabdoost, A. A. 2014. Multicriteria decisionmaking for flood management based on sustainable development criteria. International Environmental Modelling and Software Society (7th International Congress on Environment Modelling and Software). San Diego, USA.

[24] Hui, X., Wanchun, D., Yonghe, S., and Yuanwei, D. 2013. Dynamic DEMETEL group decision approach based on intuitionistic fuzzy number. 
Telkomnika, 12 (4), 1064-1072. doi: 10:12928/TELKOMNIKA.v12i4.787.

[25] Govindan, Khodaverdi, R., and Vafadarnikjoo, A. 2015. Intuitionistic fuzzy based DEMATEL method for developing green practices and performances in a green supply chain. Expert Systems with Applications, 42 (2015), 7207-7220. doi: 10.1016/j.eswa.2015.04.030.
[26] Keshavarzfard, R., and Makui, A. 2015. An IF-DEMATEL-AHP based on triangular intuitionistic fuzzy numbers (TIFNs). Decision Science Letters, 4 (2015), 237-246.

[27] Falatoonitoosi, E., Ahmed, S., amd Sorooshian., S. 2014. Expanded DEMATEL for determining cause and effect group in bidirectional relations. The Scientific World Journal, 2014 (103846), 1-7. doi:10.1155/2014/10384. 